\title{
Role of diffusion weighted imaging in diagnosis of cholesteatoma: A single centre study
}

Aida A. Abdelmaksoud ${ }^{a}$, Saeda Mohamed Abdelwahab ${ }^{b}$, Usama Kamal EldinTaya ${ }^{a}$

${ }^{\mathrm{a}}$ ENT Department, Faculty of Medicine, South Valley University, Qena, Egypt.

${ }^{\mathrm{b}}$ Radiodiagnosis Department, Faculty of medicine, South Valley University, Qena, Egypt.

\begin{abstract}
Background: Diffusion weighted imaging was introduced to improve the detection of middle ear cholesteatomas. By computed tomography, difficulty was found as cholesteatoma shows middle ear opacity similar to chronic otitis media in cases with no bone erosion,

Objectives: Purpose of this study to clarify the role of diffusion-weighted imaging in the diagnosis of cholesteatoma and differentiating it from chronic otitis media.

Patients and methods: Cross sectional study of 20 patients, All patient treated medically, followed, surgery was done in those not responding to medical treatment after one month. T2WI and DWI and ADC map were done, results assessed by SPSS system version 20 and Chi square test. Sensitivity, specificity, positive and negative predictive vales assessed.

Results: 20 patients (9 males and 11 females), ages $15-35$ and mean age $= \pm 25$ year, 10 of them showed middle ear hyperintense signal intensity lesion in T2 weighted image, restricted diffusion, and low apparent diffusion coefficient values, mean value was about $= \pm 0.75 \pm 0.26$ $\mathrm{x} 10^{-3} \mathrm{~mm}^{2} / \mathrm{s}, 11$ patients were confirmed cholesteatoma. 10 patients showed hyperintense signal intensity lesion in T2WI, facilitated diffusion and high apparent diffusion coefficient values, mean value $= \pm 1.75 \pm 0.14 \times 10^{-3} \mathrm{~mm}^{2} / \mathrm{s}, 9$ confirmed otitis media by complete resolution after antibiotic treatment and follow up. Sensitivity of diffusion-weighted imagining 90.0\%, specificity $88.9 \%$, positive and negative predictive value $90.9 \%$ and $88.9 \%$.

Conclusion: Diffusion-weighted imagining has a high sensitivity and diagnostic accuracy in differentiation of cholesteatoma from otitis media in overlapping cases.

Key words: Diffusion weighted imaging, Apparent diffusion coefficient value,Cholesteatoma, Chronic otitis media
\end{abstract}

\section{Introduction}

Cholesteatoma is a common inflammatory disease affecting the middle ear, two types of cholesteatoma detected which are pars flaccida and pars tensa, It need good surgical intervention to prevent local and intracranial complications resulting from osteoclastic activation (Fernando. M'as-Estell'es et al., 2012).

Copyright: (C) Abdelmaksoud et al. (2021) Immediate open access to its content on the principle that making research freely available to the public supports a greater global exchange of knowledge. Users have the right to Read, download, copy, distribute, print or share link to the full texts under a Creative Commons B Y-NC-SA 4.0 International License.
To assess the disease, surgery is performed as it is not adequately judged by clinical examination (Yiğiter AC et al., 2015).

Positive diagnosis of cholesteatoma is based on clinical examination, mostly by otoscopic findings and confirmed by computed tomography (CT)(Ayache D et al., 2012).

Cholesteatoma diagnosed by CT by showing opacity with rounded contours associated with 
adjacent bone erosion as tegmen tympani, ossicular chain, and scutum but with low sensitivity (43\%) and specificity (48\%). Computed tomography is mandatory for initial preoperative assessment of cholesteatoma as it can detect site, extension, and complications, however difficult assessment in overlapping cases with COM. Patient exposed to radiation also it is difficult to diagnose recurrent lesions and differentiating it from granulation tissue and secretions by CT. Differential diagnosis is important since recurrent cholesteatoma needs middle ear surgery while in granulation tissue or secretions no need for surgery (Marc $\mathbf{T}$ William et al., 2004;Blaney SP et al., 2000). Diffusion weighted imaging (DWI) depending on random fluid motion. Water molecular diffusion speed is markedly restricted in cases of infection and ischemia. This restriction is manifested as hyperintense signal intensity (SI) in diffusion sequences that can be quantified using ADC maps. Thisproduces an apparent diffusion coefficient (ADC) that forms ADC maps. Restricted diffusion lesion exhibits hyperintense SI in diffusion sequences and low ADC values in ADC map which is characteristic for cholesteatoma.

Many advantages of DWI over CT not only in preoperative status in overlapping cases of cholesteatoma and chronic otitis media but also at postoperative status confirming recurrent or residual disease (Fitzek C, et al., 2002).

Many Contrast-enhanced MRI advantages depicted including superior tissue contrast resolution, no radiation exposure, differentiates solid from cystic lesions, but its disadvantages expensive, long examination time and need for contrast medium(Williams MT, et al., 2003). DWI needs no contrast media also is done within a shorter examination time than contrast-enhanced MRI(Bammer R., 2003).

Cholesteatomas are hyperintense on DWI obtained with b-factors of 500 or 1000 $\mathrm{s} / \mathrm{mm}^{2}$ (Chen $\mathrm{S}$ et al., 2001).

T2 shine-through effect or restricted molecular diffusion of cholesteatoma is the cause of high signal intensity. T2 shine-through effect is seen in lesions with prolonged relaxation time. DWI is a reliable tool for the prevention of unnecessary second-look surgeries in suspected cholesteatomas and is also a valuable alternative to CT (Cimsit NC, et al., 2010).

Many artifacts of DWI can be generated during the acquisition as motion artifacts, susceptibility artifacts, eddy current artifacts, ghosting artifacts with the risk of false-positive results (De Foer B, et al., 2006).

In this study, we aimed to assess the diagnostic reliability of DWI in the detection of cholesteatoma and its differentiation from overlapping chronic otitis media. No need for use of the contrast media in this study.

\section{Patientand Methods}

This observational cross sectional study was carried out after submission and approval of the local ethics committee of our institution. It was done at the radiology department after cooperation with the ENT department; informed written consent was taken from all patients. 9 males and 11 females, age ranged from 15-35 year with a mean age of $= \pm 25$ year were included in this study between march 2019 and march 2020, all patient complaining of ear discharge and some hearing loss were included in this study with exclusion of those who were claustrophobic, with metallic stenting, brain clips, MRI study including axial T2WI and DWI, No need for sedation or anesthesia in all 
patients, No contrast media injected. All patients treated with antibiotic and followed, Surgery was done in patients not responding to medical treatment after one month duration. Non of them exposed to previous surgery.

MRI protocol: It was done with a superconducting philips scanner (achieva, 1.5 tesla philips, Health care, Best, The Netherlands) after patients informed written consent were taken and after exclusion of MRI contraindications, 8 channel head coil used, T2WI and DWI sequences were taken, No contrast media injected. The following sequences were used:

1- Axial T2WI with the following parameters: T2WI, TE $100 \mathrm{~ms}$, TR $4.4 \mathrm{~s}$, FOV $240 \mathrm{~mm}$, slice thickness 5.0/0.1 mm, flip angle 900 .

2- Axial non echo-planar single-shot turbo spin-echo diffusion-weighted imaging, the following parameters: $3.0 / 0.3 \mathrm{~mm}$ slice thickness, TE: $105 \mathrm{~ms}$, TR: $1.8 \mathrm{~s}, \mathrm{FOV}: 160$ $\mathrm{mm}$, diffusion factor: B $1000 \mathrm{~s} / \mathrm{mm} 2$. Acquisition time $2 \mathrm{~min}$ and $50 \mathrm{~s}$, flip angle 90 . Different $b$ values $b=0$ and $1000 \mathrm{~mm}^{2} / \mathrm{s}$. Postprocessed ADC map was reconstructed.

Image analysis: The following sequences for all cases are revised: T2WI, DWI and ADC map, ROI inserted in area of interest away from the bony parts around and mean ADC value was calculated. ROI placed at the site of the middle ear lesion, Mean ADC values were expressed in $10^{-3} \mathrm{~mm}^{2} / \mathrm{s}$.

STATISTICS data was analyzed using SPSS version 20 as the following:

- Quantitative data was represented as mean, standard deviation, median and range.

- Qualitative data was presented as number and percentage and compared using Chi square test.
- Sensitivity, specificity, positive, negative predictive value and accuracy of different diagnostic methods were calculated. $\mathrm{P}$ value was considered significant if it was less than 0.05 .

\section{Results}

20 cases (11 females and 9 males) their age 15-35 and mean age $= \pm 25$ presented with middle ear discharge exposed to clinical examination, size of the lesions were $\pm 3-18$ $\mathrm{mm}$ and mean value was $10.5 \mathrm{~mm}$ followed by MRI and DWI study, their size ranging from $\pm 2-18 \mathrm{~mm}$ and mean value about $10 \mathrm{~mm}, 20$ patients exposed to DWI, 10 of them showed middle ear hyperintense SI lesion in T2WI, restricted diffusion in DWI and had low ADC values, mean value was about $= \pm 0.75 \pm 0.26$ $\times 10^{-3} \mathrm{~mm}^{2} / \mathrm{s}, 11$ were confirmed cholesteatoma surgically (Fig1:3). 10 patients showed middle ear hyperintense SI lesion in T2WI and facilitated diffusion in DWI and high ADC values, mean value $= \pm 1.75 \pm 0.14 \times 10^{-3}$ $\mathrm{mm}^{2} / \mathrm{s}, 9$ confirmed chronic otitis media by complete resolution after antibiotic treatment and follow up. (Fig.2) One false-negative case of these not responding to medical treatment, surgically operated and proved to be small cholesteatoma $2 \mathrm{~mm}$. Different ADC values of 20 lesions were described in table- 1 . The sensitivity of DWI with added ADC values was $90.0 \%$, specificity $88.9 \%$, positive predictive value $90.9 \%$, negative predictive value $88.9 \%$. Shown in Table2.

Table1.ADC values $x 1^{-3}$ in cases of cholesteatoma and chronic otitis media.

\begin{tabular}{|l|l|l|}
\hline N0 & Cholesteatoma & COM \\
\hline 1 & 0.41 & 1.61 \\
\hline 2 & 0.65 & 1.73 \\
\hline 3 & 0.70 & 1.81 \\
\hline
\end{tabular}




\begin{tabular}{|l|l|l|}
\hline 4 & 0.75 & 2.15 \\
\hline 5 & 0.63 & 1.54 \\
\hline 6 & 0.80 & 1.63 \\
\hline 7 & 0.65 & 1.72 \\
\hline 8 & 0.67 & 1.87 \\
\hline 9 & 0.80 & 1.71 \\
\hline 10 & 0.71 & \\
\hline 11 & 1.50 & \\
\hline Mean \pm & $0.75 \pm 0.26$ & $1.75 \pm$ \\
SD & & 0.14 \\
\hline
\end{tabular}

Table1. ADC values in cases of cholesteatoma and chronic otitis media, mean ADC value of cholesteatoma was $0.75 \pm 0.26 \times 10^{-3} \mathrm{~mm}^{2} / \mathrm{s}$ and that of chronic otitis media about $1.75 \pm 0.14$ $\mathrm{x} 10^{3} \mathrm{~mm}^{2} / \mathrm{s}$.

Table2.Results of DWI with added ADC values of cholesteatoma.

\begin{tabular}{|l|c|}
\hline Results & Percentage \\
\hline Sensitivity & $90.9 \%$ \\
\hline Specificity & $88.9 \%$ \\
\hline $\begin{array}{l}\text { Positive predictive } \\
\text { value }\end{array}$ & $90.9 \%$ \\
\hline $\begin{array}{l}\text { Negative predictive } \\
\text { value }\end{array}$ & $88.9 \%$ \\
\hline
\end{tabular}

Table-2: Shows the sensitivity of DWI and ADC values was $90.0 \%$, specificity $88.9 \%$, positive predictive value $90.9 \%$, negative predictive value $88.9 \%$.
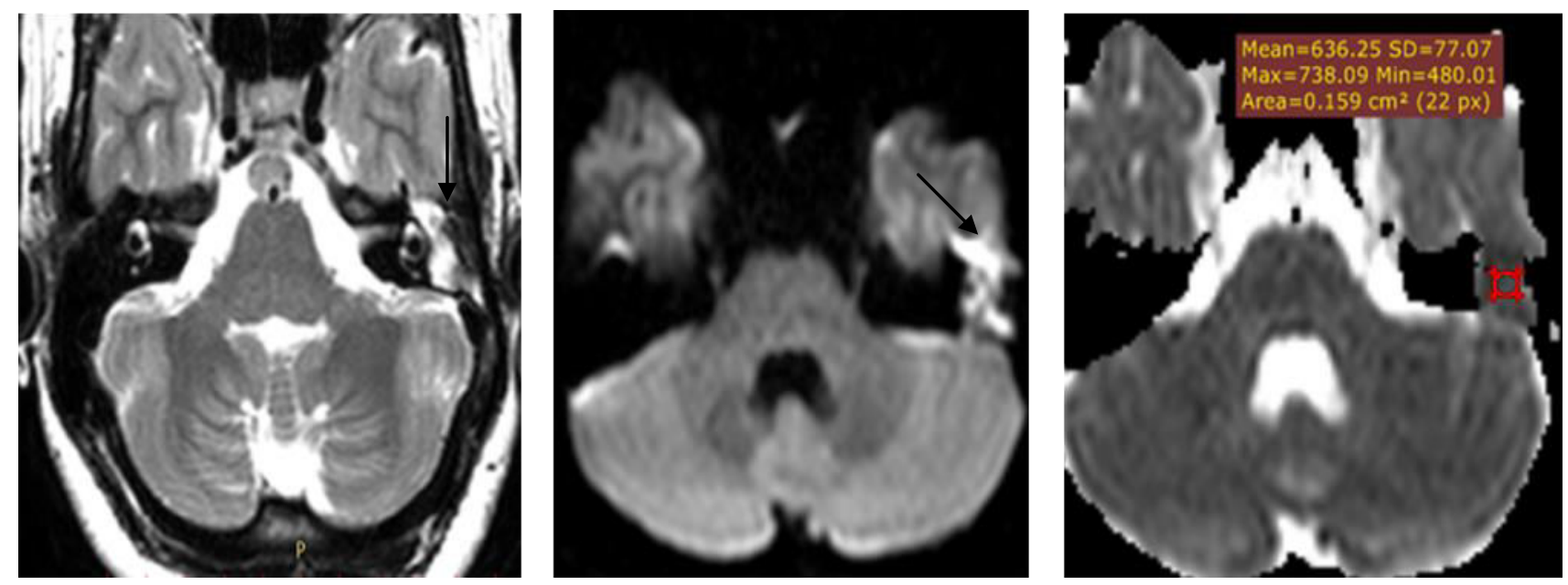

Fig. 1.A 17-year-old female patient complaining of left ear persistent discharge inspite of antibiotic treatment (a) T2WI shows hyperintense SI lesion filling the left middle ear cavity (black arrow) (b) DWI shows left middle ear hyperintense SI lesion (black arrow) (c) ADC map shows hypointense SI and its value was about $0.636 \times 10^{-3} \mathrm{~mm}^{2} / \mathrm{s}$. It was surgically proved cholesteatoma. 

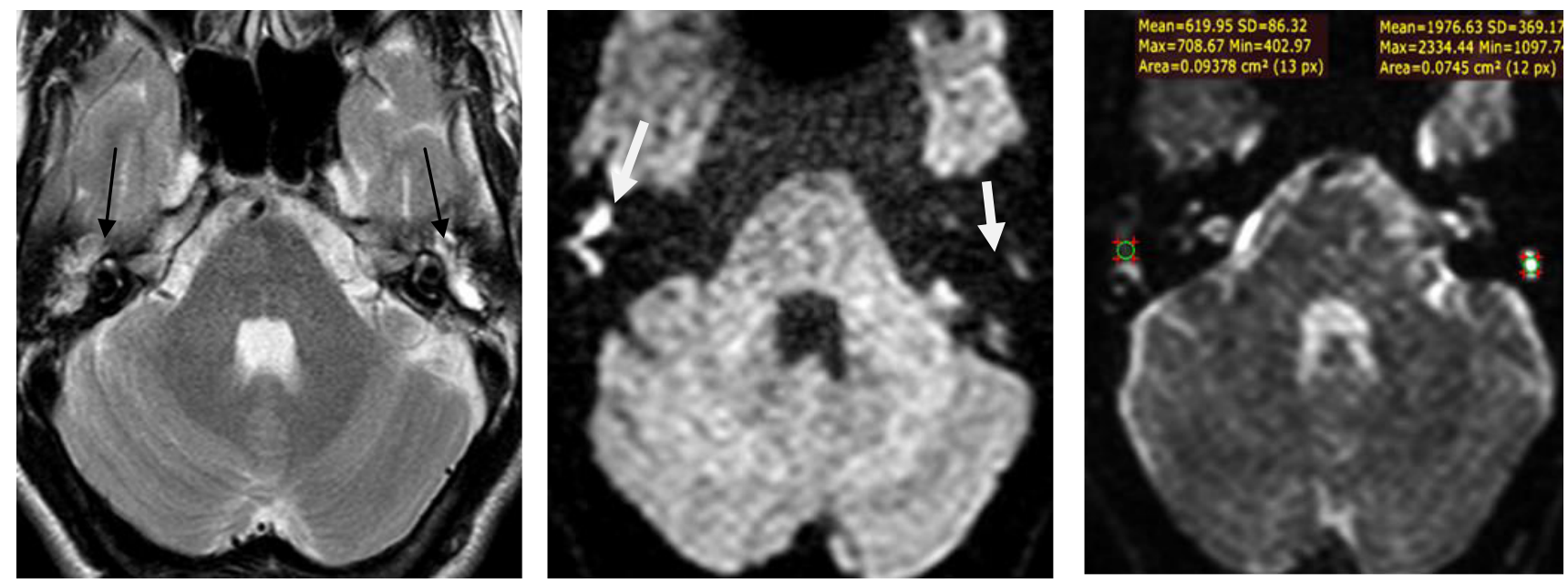

Fig. 2.A 18-year-old male patient complaining of bilateral ear discharge, (a) T2WI shows bilateral middle ear hyperintense SI lesions (black arrow) (b) DWI shows hyperintense SI lesion in right ear and hypointense SI lesion in the left middle ear (white arrows) (c) ADC map shows right sided hypointense SI lesion and its ADC value about $0.619 \times 10^{-3} \mathrm{~mm}^{2} / \mathrm{s}$ and left sided hyperintense SI and ADC value about $1.97 \times 10^{-3} \mathrm{~mm}^{2} / \mathrm{s}$. Right middle ear lesion surgically proved cholesteatoma and left one proved chronic otitis media healed on antibiotic treatment.
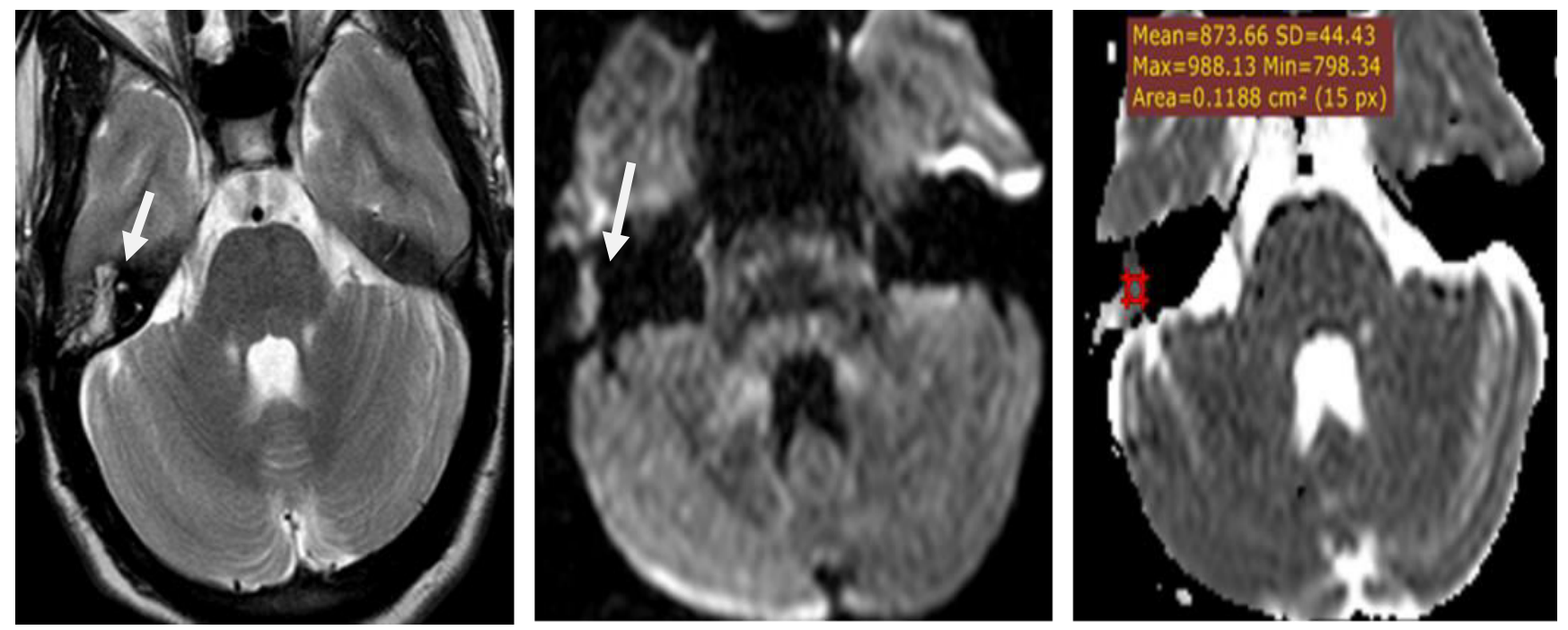

Fig. 3.A 19-year-old female patient complaining of right ear discharge, (a) T2WI shows hyperintense SI lesion filling the right middle ear (white arrow) (b) DWI shows right middle ear hyperintense SI lesion (white arrow) (c) ADC map shows right sided hypointense SI lesion and its ADC value was about $0.873 \times 10^{-3} \mathrm{~mm}^{2} / \mathrm{s}$. Surgically proved cholesteatoma. 


\section{Discussion}

Cholesteatomas may be primary or secondary acquired middle ear chronic inflammatory lesions. It requires complete surgical resection. Reasons for cholesteatoma still under research. Diseased mucosa contribute to the development of retraction pockets and cholesteatoma (Louw L.2010).

Computed tomography is the initial imaging technique often used for pre and postoperative diagnosis that shows a mass in the typical location associated with bone destruction so cholesteatoma is considered, with no bone destruction, findings not specific as chronic otitis media or infected granulation tissue show same CT criteria (Jeunen G, et al., 2008).

Near similar results of a study stated that, The sensitivity of RESOLVEDWI in cholesteatoma was $88 \%$, specificity was $96 \%$, While the accuracy was 92\%(Fischer N,et al., 2019)

DWI specificity, sensitivity, positive and negative predictive values were $85.7 \%, 100 \%$, $96.8 \%$ and $100 \%$, respectively, these results are higher than our results (Gehan G, et al., 2019)

ADC median value of the cholesteatoma group $\left(0.84 \times 10^{-3} \mathrm{~mm}^{2} / \mathrm{s}\right)$ while that of our result $\quad \pm \quad 0.75 \times 10^{-3} \mathrm{~mm}^{2} / \mathrm{s}$ (CavaliereM, et al., 2018).

Soft tissue characterization is better by MRI than CT. For cholesteatoma diagnosis, DWI confirms its high diagnostic value. Cholesteatoma exhibits diffusion restriction giving high SI in DWI (Dietrich O, et al., 2010)

DWI has no radiation exposure, No need for contrast material and short examination time compared with $\mathrm{CT}$ and MRI, Small sample size is the limitation of this study.
Near similar results proved by (AkkariaMJ, et al., 2014) that showed of 97 cases. 74 cholesteatomas were diagnosed at surgery. Diffusion-weighted and delayed contrast-enhanced T1weighted sequences had a sensitivity of $84.9 \%$ and $90.4 \%$, a specificity of $87.5 \%$ and $75 \%$, a positive predictive value of $95.4 \%$ and $91.7 \%$, and a negative predictive value $65.6 \%$ and $72 \%$ respectively

(Clemens Fitzek, et al., 2002) showed results similar to our result stated that 13 of 15 patients with cholesteatomas showed hyperintense SI in DWI, whereas 10 of 12 patients with chronic otitis media showed the usual hypointense SI of the middle ear.

\section{(Manuel}

Mateos-

Fernández,2012).Proved that positive, negative predictive values of DWI, sensitivity and specificity were, $92.85 \%$, and $92.30 \%, 92.85 \%$ and $92.30 \%$, respectively and these results are slightly higher than our study results.

Study results of (Ahmed FA, 2015) proved that sensitivity, specificity, and positive predictive value $100 \%$ for DWI for recurrent cholesteatoma. In 3 cases of a study proved Positive predictive value was $100 \%$. The surgical approach was determined from combined CT and MRI results. This discussed by (Isabelle PlouinGaudon, et al., 2010).

(Ilıca AT, 2010) demonstrated higher results than our results stated that sensitivity of $94 \%$, specificity, and positive predictive value of $100 \%$ of DWI in cholesteatoma diagnosis.

(GökselTuzcu, et al., 2015). Proved that91 cases suspected of cholesteatoma were operated. According to the results of operations, 50 patients had cholesteatoma and 41 patients had 
granulation tissue. The mean $\mathrm{ADC}$ values of cholesteatoma were significantly lower than patients with granulation tissue $(p<0.05)$. The sensitivity and specificity of EPDWI in detection of cholesteatoma were $97.6 \%$ and $92.0 \%$, respectively these results agreed with this study.

19 of 30 cases showed areas of DWI restriction within the middle ear denoting cholesteatoma. All 19 cases that showed evidence of recurrent cholesteatoma on DWI MRI images surgically proved. Of the 11 cases that were negative for cholesteatoma on DWIs, 9 of these cases underwent second look mastoid surgery with 4 cases showed small cholesteatomas while the other 5 cases granulation tissue (56\%) (Medany et al., 2018). The sensitivity, specificity, negative/positive-predictive, and overall-agreement values of DWI technique were $100 \%, 78 \%, 100 \%$, $74 \%$, and $87 \%$; respectively stated by (Algin O, et al., 2017).

DWI detected 21 out of 20 cases proved cholesteatoma patients (sensitivity $100 \%$, specificity $90 \%$, PPV $95.2 \%$ and $\mathrm{P}$ value is 0.001 ). Specificity was $100 \%$. The ADC of cholesteatoma.Similar results as regard Cut off value of cholesteatoma that was $\leq 0.759 \times$ $10^{-3} \mathrm{~mm}^{2} / \mathrm{s}$ confirmed by (Nasr MM, et al., 2017).

This study stress DWI finding and ADC values of the middle ear lesions, It is avaluabletool in diagnosis of cholesteatoma and differentiating it from otitis media, Limitation of this study is the small sample size.

\section{Conclusion}

Diffusion-weighted imagining combined with ADC values has high specificity and diagnostic accuracy in the differentiation of cholesteatoma from chronic otitis media mainly in overlapping cases. Limitations of this study is the small sample size.

\section{Recommendation}

It is recommended to make a study on large number of cases.

\section{Conflict of interest: None}

Abbreviations

DWI: Diffusion weighted imaging.

T2WI: T2 weighted imaging.

MRI: Magnetic resonance imaging.

ADC: Apparent diffusion coefficient.

SI: Signal Intensity.

COM: Chronic otitis media.

CT: Computed tomography.

SPSS: Statistical package for the social sciences.

\section{References}

Ahmed FA.(2015). Diagnosis of recurrent cholesteatoma using diffusion weighted MRI. ejrnm, Egyptian Journal of Radiology and Nuclear Medicine, 46, 391-395.

Akkari M, Gabrillargues J, Saroul N, Pereira B, Russier M, Mom T, et al. (2014). Contribution of magnetic resonance imaging to the diagnosis of middle ear cholesteatoma: analysis of a series of 97 cases. Eur Ann Otorhinolaryngol Head Neck Dis, 131(3):153-8.

Ayache D, Darrouzet V, Dubrulle F, Vincent C, Bobin S, Williams $M$, et al. (2012).Imaging of nonoperated cholesteatoma: clinical practice guidelines. Eur Ann Otorhinolaryngol Head Neck Dis, 129(3):148-52.

Bammer R. (2003). Basic principles of diffusion-weighted imaging.Eur $\mathrm{J}$. Radiol, 45: 169-184 [PMID: 12595101].

Blaney SP, Tierney P, Oyarazabal M, Bowdler DA (2000). CT scanning in "second look" combined approach tympanoplasty. Rev 
Laryngol Otol Rhinol (Bord), 121(2):79-81.

Chen S, Ikawa F, Kurisu K, Arita K, Takaba J, Kanou Y (2001). Quantitative MR evaluation of intracranial epidermoid tumors by fast fluid-attenuated inversion recovery imaging and echo-planar diffusion-weighted imaging. AJNR Am J Neuroradiol, 22:1089-1096 [PMID: 11415903].

Cimsit NC, Cimsit C, Baysal B, Ruhi IC, Ozbilgen S, Aksoy EA (2010). Diffusion-weighted MR imaging in postoperative follow up: reliability for detection of recurrent cholesteatoma. Eur J. Radiol, 74: 121-123 [PMID: 19231123 DOI: 10.1016/j.ejrad.2009.01.025].

Fitzek C, Mewes T, Fitzek S, Mentzel HJ, Hunsche S, Stoeter P. (2002). Diffusion-Weighted MRI of Cholesteatomas of the Petrous Bone Journal of Magnetic Resonance Imaging, 15:636-641.

Dietrich O, Biffar A, Baur-Melnyk A, Reiser MF. (2010).Technical aspects of MR diffusion imaging of the body.Eur J Radiol, 76:314-22.

De Foer B, Vercruysse JP, Pilet B, Michiels J, Vertriest R, Pouillon M, et al.(2006). Single-shot, turbo spin-echo, diffusion-weighted imaging versus spin-echo-planar, diffusion-weighted imaging in the detection of acquired middle ear cholesteatoma. AJNR Am J Neuroradiol, 27(7):1480-2.

Fitzek C, Mewes T, Fitzek S, Mentzel HJ, Hunsche S, Stoeter P. (2002). Diffusion-weighted MRI of cholesteatomas of the petrous bone. J Magn Reson Imaging, 5(6):636-41.

Fernando $M{ }^{\prime}$ as-Estell'es, $M$. Mateos-Fern'andez, B. Carrascosa-Bisquert, et al., (2012).Contemporary non-echoplanar diffusion-weighted imaging of middle
Cholesteatomas.Radiographics,32:

1197-1213.

Cavaliere M, Di Lullo AM, Cantone E, Scala G, Elefante A, Russo C, et al. (2018). Cholesteatoma vs granulation tissue: a differential diagnosis by DWI-MRI apparent diffusion coefficient. Eur Arch Otorhinolaryngol, 275(9):22372243.

GehanGA, Leila RE, Enas AI, Sherif K. (2019). Role of DiffusionWeighted Propeller Magnetic Resonance Imaging in Cholesteatoma

Diagnosis 129, Volume 87,

Page 2477-2484.

Göksel T, Yardımcı AH, Turna Ö, Göner RE, Acıŏlu E.(2015). Kronik süpüratif otitis medialı hastalarda kolesteatom ve granülasyon dokusu ayrımında difüzyon ağırlıklı manyetik rezonans görüntülemenin önemi [Importance of diffusion weighted magnetic resonance imaging at differentiation of cholesteatoma and granulation tissue in patients with chronic suppurative otitis media]. Kulak Burun Bogaz Ihtis Derg, 25(5):25565.

Ilıca AT, Hıdır Y, Bulakbaşı N, Satar B, Güvenç I, Arslan HH, Imre N.(2012). HASTE diffusionweighted MRI for the reliable detection of cholesteatoma. Diagn Interv Radiol, 18(2):153-8.

Plouin-Gaudon I, Bossard D, Ayari-Khalfallah S, Froehlich P.(2010). Fusion of MRIs and CT scans for surgical treatment of cholesteatoma of the middle ear in children. Arch Otolaryngol Head Neck Surg, 136(9):878-83.

Jeunen G, Desloovere C, Hermans R, Vandecaveye V.(2008). The value of magnetic resonance imaging in the diagnosis of residual or recurrent acquired cholesteatoma 
after canal wall-up tympanoplasty. Otol Neurotol, 29(1):16-8.
Louw
L.
(2010).Acquired
cholesteatoma
stepwise pathogenesis: explanations.

J.LaryngolOtol, 124:587-93.

Manuel MF. (2012). The Role of Diffusion-Weighted Magnetic Resonance Imaging in Cholesteatoma Diagnosis and Follow-up: Study with the Diffusion PROPELLER Technique. ActaOtorhinolaringolEsp, 63(6):436442.

Williams MT, Ayache D. (2004). Imaging of the postoperative middle ear. Eur Radiol, 14(3):482-95.

Medany, et al., (2018). Reliability of Diffusion Weighted MRI for the Diagnosis of Residual and Recurrent Cholesteatoma. The Egyptian jounal of hospital medicine, 72: 5403-5408.

Nasr MM. Osman, Abdel RahmanA, Moustafa TA, (2017). The accuracy and sensitivity of diffusion-weighted magnetic resonance imaging with Apparent Diffusion Coefficients in diagnosis of recurrent cholesteatoma, European journal of radiology, 4, P2739, DOI:https://doi.org/10.1016/j.ejro. 2017.03.001

Fischer N, Schartinger VH, Dejaco D, Schmutzhard J, Riechelmann $\mathbf{H}$, Plaikner M, et al. (2019). ReadoutSegmented Echo-Planar DWI for the Detection of Cholesteatomas: Correlation with Surgical Validation. AJNR Am J Neuroradiol, 40(6):10551059.

Algin O, Aydın H, Ozmen E, Ocakoglu G, Bercin S, Porter DA, et al.(2017). Detection of cholesteatoma: High-resolution DWI using RS-EPI and parallel imaging at 3 tesla. J Neuroradiol ,44(6):388-394.

Williams MT, Ayache D, Alberti C, Héran F, Lafitte F, Elmaleh-Bergès M, Piekarski JD (2003). Detection of postoperative residual cholesteatoma with delayed contrast-enhanced MR imaging: initial findings. Eur Radiol, 13(1):169-74.

Yiğiter AC, Pınar E, İmre A, Erdoğan N. (2015). Value of EchoPlanar Diffusion-Weighted Magnetic Resonance Imaging for Detecting Tympanomastoid Cholesteatoma. J Int Adv Otol, 11(1):53-7. 